\title{
RESEARCH
}

Open Access

\section{Trends and predictors of inequality in childhood stunting in Nepal from 1996 to 2016}

\author{
Mirak Raj Angdembe ${ }^{1 *}$ (D) Bishnu Prasad Dulal ${ }^{1 \dagger}$, Kreepa Bhattarai $^{2+}$ and Sumit Karn ${ }^{3+}$
}

\begin{abstract}
Background: Although decreasing in trend, one-in-three children remain stunted in Nepal and its distribution is unequal among different socioeconomic and geographical subgroups. Thus, it is crucial to assess inequalities in stunting for designing equity focused interventions that target vulnerable groups with higher burden of stunting. This study measures trends and predictors of socioeconomic inequalities in childhood stunting in Nepal.

Methods: Data from five rounds (1996-2016) of Nepal Demographic and Health Survey, nationally representative cross-sectional surveys, were used. Levels and trends of absolute and relative disparity in stunting between the poorest and the richest wealth quintiles, and among all quintiles were assessed by calculating absolute and relative difference, concentration curve and index. Average marginal effects of predictors on stunting were calculated using probit regression. The concentration index was subsequently decomposed into contributing factors.
\end{abstract}

Results: Even though stunting consistently declined in all wealth quintiles between 1996 and 2016, reduction was relatively higher among the richer quintiles compared to poorer ones. The absolute difference between the poorest and the richest quintile increased from 24.7 in 1996 (64.5\% in poorest - 39.8\% in richest) to 32.7 percentage points in 2016 (49.2-16.5\%). The relative disparity also increased; the ratio of stunting in the poorest to the richest quintile was 1.6 in 1996 and 3.0 in 2016. The concentration index increased (in absolute value) from - 0.078 in 1996 to -0. 147 in 2016 indicating that stunting was disproportionately concentrated in poorer households and socioeconomic inequalities worsened from 1996 to 2016. Decomposition analysis revealed that in 1996, wealth (61\%), caste/ ethnicity (12\%), mother's education (12\%) and birth order (9\%) were the major contributors to observed socioeconomic inequalities in stunting; while in 2016, wealth (72\%), mother's BMI (12\%) and birth order (9\%) were the major contributors.

Conclusions: Despite remarkable improvements in average stunting over the last two decades, substantial socioeconomic inequalities in stunting exists and is determined not only by immediate factors but also by underlying and contextual factors which emphasize the need for coherent actions across different sectors. In addition to reducing inequalities in wealth, nutrition programming should be focused on most disadvantaged subgroups which are prone to both stunting and relative poverty.

Keywords: Concentration index, Decomposition, Predictors, Nepal, Nepal demographic and health survey, Socioeconomic inequalities, Stunting

\footnotetext{
* Correspondence: mirak.angdembe@gmail.com

†Bishnu Prasad Dulal, Kreepa Bhattarai and Sumit Karn contributed equally to this work.

${ }^{1}$ HERD International, Thapathali-11, Kathmandu, Nepal

Full list of author information is available at the end of the article
}

(c) The Author(s). 2019 Open Access This article is distributed under the terms of the Creative Commons Attribution 4.0 International License (http://creativecommons.org/licenses/by/4.0/), which permits unrestricted use, distribution, and reproduction in any medium, provided you give appropriate credit to the original author(s) and the source, provide a link to the Creative Commons license, and indicate if changes were made. The Creative Commons Public Domain Dedication waiver (http://creativecommons.org/publicdomain/zero/1.0/) applies to the data made available in this article, unless otherwise stated. 


\section{Introduction}

Under-nutrition is still a major barrier for child growth and development in developing countries. Low height-for-age or stunting is an important indicator for assessing undernutrition among children. It represents the devastated result of poor nutrition over a long period, in children under-five years [1]. Stunting can happen in the first 1000 days of child's life after conception and is worsened by recurrent and chronic illnesses $[2,3]$. Coupled with micronutrient deficiencies, affected children may suffer from irreversible brain damage, impeding their complete developmental potential. Even survivors are more likely to lead diminished lives, have compromised cognitive abilities, reduced school performance, lowered economic productivity and are at a greater risk of nutrition-related chronic diseases later in life $[2,4]$.

Globally, 150 million children under-five were stunted in 2017, of which, more than half (55\%) were Asian [5]. Although undernutrition is decreasing globally, stunting is declining relatively at a slower pace, threatening the achievement of international commitments [6]. At 36\% in 2016, stunting is still unacceptability high in Nepal with a slow rate of decline (57\% in 1996 and 2001, 49\% in 2006, 41\% in 2011) [7-11]. Masked by national average, stunting and severe stunting in some parts of the country are even higher and wide variation between different socioeconomic and geographical subgroups is worrisome. In 2016, stunting was higher in the mountain region $^{1}(47 \%)$ where access to health care and other services is particularly poor, Karnali province ${ }^{2}(55 \%)$, children born to mothers with no education (46\%) and children belonging to households in the poorest wealth quintile (49\%) [10].

Childhood stunting is considered to be the best overall indicator of children's well-being that reflects social inequalities [12]. It is associated with a multitude of demographic, socioeconomic and nutritional factors such as child's age, gender, dietary intake, household economic status, mother's education, mother's age and household food insecurity [2, 13]. Nevertheless, food insecurity, mother's education and household income were considered as the most important predictors $[2,14-16]$. Whereas the major contributors to socioeconomic disparities in stunting and their changes over time were household economic status and sanitation, parental education, utilization of health services (antenatal care, delivery at health facility), maternal short stature, child's age, birth order, duration of breastfeeding and ethnicity [17-19].

The Government of Nepal is committed to achieving the Sustainable Development Goals (SDG) 2030 principled on 'leaving no one behind'. These goals necessitate disaggregation of data by multiple dimensions including wealth [20]. With equity and access as one of the strategic pillars; inclusion and disaggregated data needs are recurring motifs in Nepal's current health sector strategy 2015-2020 [21]. To provide momentum towards universal health coverage as envisioned by the sectoral strategy, an enriched understanding of who and where the disadvantaged and vulnerable children are, is thus important. To this end, efforts have been underway. Nepal joined the 'scaling up nutrition' movement in 2011 to strengthen political commitment and accountability for ending malnutrition. Efforts have also been seen in the form of nutrition specific and sensitive interventions through different sectors under the common framework of Multi-Sector Nutrition Plan [22]. However, these are still relatively recent and may not be widespread enough to reach the most vulnerable and impoverished population [15].

Given that one-in-three children remain stunted and its distribution is unequal among different population subgroups, understanding inequalities in stunting is crucial for designing equity focused interventions. In this context, this study aims to assess the levels and trends in childhood stunting by wealth quintile (a measure of household economic status) in Nepal; use absolute and relative measures including concentration index to capture inequality across all quintiles; and then 'decompose' these inequalities by quantifying the contributions attributable to each predictors and examine their changes over time. To our knowledge this is the first study to investigate drivers of disparities in stunting and their trends in Nepal.

\section{Methods}

Data

We used data from five rounds of Nepal Demographic and Health Surveys (NDHS) conducted in Nepal in 1996 (originally called Nepal Family Health Survey, NFHS), 2001, 2006, 2011 and 2016. The datasets were downloaded with permission from the DHS program. NDHS are nationally representative cross-sectional household surveys that provide data for a wide range of indicators in the areas of population, health and nutrition. They use two-stage or three-stage, systematic cluster random sampling design. Sample size and response rates are presented in Table 1. The NDHS reports can be referred to for further detail [7-11].

The 1996 and 2001 surveys did not calculate the wealth index factor scores in original datasets. These are available as separate files. Similarly, the updated anthropometric z-scores based on 2006 World Health Organization's (WHO) child growth standards [23] are also available as separate files for these surveys.. Data from these separate files were thus merged with the datasets of 1996 and 2001. 
Table 1 Number of households, response rate, number of children and time of field work by survey year

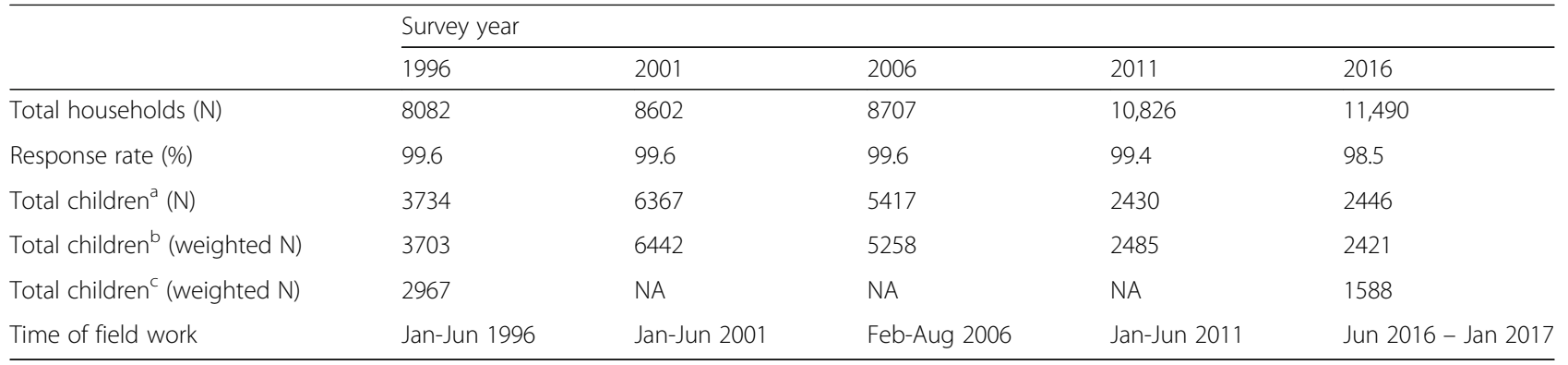

${ }^{a}$ In 1996 anthropometric data were collected for under-three years old children; in 2001, 2006, 2011 and 2016 anthropometric data were collected for under-five years old children

${ }^{b}$ Sample size used for calculating the quintile specific trends, concentration curves, levels and trends in concentration indices and absolute and

relative differences

'Sample size used for decomposition analysis to explain between-year changes in inequalities comparing 1996 and 2016

NA: Not applicable

The 1996 survey collected anthropometric data for all children under-three years of age born in the three years before the survey to women interviewed. We used children's recode dataset for all calculations of 1996. Other surveys collected anthropometric measurements for under-five years' de facto children - those who stayed in the household the night before the interview. So except for 1996 survey, we used household member recode datasets which contain information for all children under-five in the household for calculating the quintile specific trends, concentration curves, levels and trends in concentration indices and absolute and relative differences (Weighted $\mathrm{N}$ : 1996-3703; 2001-6442; 2006-5258; 2011-2485; 20162421). For decomposition analysis of 1996 and 2016, we used children recode dataset for characteristics of children and their mother (Weighted N: 1996-2967; 2016-1588).

\section{Outcome variable}

Compared to underweight and wasting, both of which reflect recent nutritional distress, stunting is a result of chronic nutritional deprivation [24]. Although all three indicators are equally important to measure nutritional imbalance resulting in undernutrition, we analysed stunting among children as outcome to better measure inequalities in long term nutritional progress in Nepal. Stunting was measured using height-for-age z-scores. The WHO child growth standard [23] expresses a child's height in standard deviation units (z-scores) above or below the median height of healthy children in the same age group or in a reference group. Using this standard, we classified children whose height-for-age z-score was below minus two standard deviations $(<-2 \mathrm{SD})$ from the median of the reference population as short for their age (stunted) or chronically malnourished.

\section{Conceptual framework}

The WHO's conceptual framework on childhood stunting [25] explains the context, causes and consequences of stunting and underpins our analysis. The process of stunting begins even before birth. Maternal factors such as short maternal stature, intrauterine growth retardation, short birth spacing and poor nutrition during pre-conception, pregnancy and lactation contributes to stunted growth and development of the child. After birth, breastfeeding practices become important and household factors such as inadequate sanitation affects the risk of infection and morbidities that interfere with growth. Wider contextual factors, among many others, include wealth, education, socio-cultural factors such as caste/ethnicity, and access to health care. Together with wealth and education, caste/ethnicity determines the socioeconomic position of populations placing certain groups at an advantage in terms of access and use of resources while marginalizing others.

Differences in exposure and vulnerability to poor health outcomes are linked to people's respective social status [26]. In Nepal, significant disparities in access to health care among people of different caste/ethnic groups exist [27]. Food consumption patterns [28] including complementary feeding practices [29] also vary between different sociocultural groups affecting their nutritional status. In health care access, antenatal care (ANC) visits and delivery in health facility are usually the first points of contact with the health system for most pregnant women. These are critical windows of opportunity for health programs to provide evidence-based interventions likely to prevent stunting in utero and later.

\section{Predictors of socioeconomic inequalities}

We used the conceptual frame work and previously published literatures [13, 19, 30-32] that have shown strong association between either stunting or height-for-age z-scores and socioeconomic, maternal, child and Water, Sanitation and Hygiene (WASH) factors to guide the selection of our predictor variables. Our selections were 
also restricted by what was available in the 1996 NDHS dataset.

In socioeconomic factors, first we included household wealth index. Income and wealth enables access to better quality foods, health care and other factors that can raise the nutritional status of children [33]. The NDHS calculates wealth index (also called the asset index) composed of a set of variables asked in household questionnaires that describe household assets and utilities. It is a composite measure of a household's cumulative living standard and is used as a proxy for household welfare. Households are given scores based on the number and kinds of consumer goods they own, ranging from a television to a bicycle or car, and housing characteristics such as source of drinking water, toilet facilities, and flooring materials [10]. Constructed using principal component analysis, scores for the first principal component gives the index and individual households are placed on a continuous scale of relative wealth. The quintiles are then constructed with each quintile containing $20 \%$ of the population.

Second we included caste/ethnicity. The caste variable recoded $^{3}$ by NDHS was adapted for analysis into following groups: Brahmin/Chhetri, Dalit, Janajati, Muslim, Newar, other terai caste and others. The category 'others' was later omitted during model fitting to minimize errors. Maternal and parental factors included education level of mother and her husband/partner, height $(\mathrm{cm})$, body mass index (BMI), ANC visits and delivery in a health facility. Child characteristics consisted of age (months), birth order, status of breastfeeding and perceived size of baby at birth. WASH factors comprised availability of toilet facilities in household. We used these predictor variables in decomposition analysis to explain between-year changes in inequalities comparing 1996 and 2016.

\section{Measurement of socioeconomic inequalities}

We started with comparison of stunting across different wealth quintiles. We then used both absolute and relative measures of inequality for comprehensive assessment of household economic disparities in stunting, as using either one only can lead to dissimilar inferences about the magnitude and changes [34]. We calculated one absolute (the difference between stunting in the poorest/first and richest/fifth quintiles) and two relative indicators of inequality (the ratio of stunting in the poorest quintile to the richest quintile and the concentration curve/index).

The concentration curve and index captures inequality across all wealth quintiles. The concentration curve plots the cumulative proportion of stunting against the cumulative proportion of children, ranked by wealth index, beginning with the poorest, and ending with the richest (x-axis). We constructed concentration curves for 1996 and 2016 to illustrate changes in inequality in stunting between these survey periods and also applied statistical test of dominance [35] between the concentration curves to assess whether differences between curves are significant.

To quantify the degree of socioeconomic inequality in stunting we calculated the concentration index which is defined as twice the area between the stunting concentration curve and the line of equality (the diagonal or 45-degree line; see Fig. 2) [35]. The index is expressed in a scale ranging from -1 to 1 ; a value of zero represents perfect equality, whereas a value of 1 to -1 indicates that only the richest or the poorest household bear the burden of stunting. It is negative (positive) when the curve lies above (below) the line of equality, indicating a higher relative burden of stunting among the poor (rich). When we multiply the value of concentration index by 75 we get an estimation of the percentage of stunting to be redistributed from the richer half to the poorer half, in order to reach a distribution of perfect equality and to obtain an index value of zero [36]. In our analysis, since the outcome variable is dichotomous, the bounds of the concentration index are not -1 and 1 but depend on the mean of the variable. To ensure robustness, we further normalized the standard index estimates by dividing through by 1 minus the mean [37] and presented the results.

The concentration index can be written in terms of the covariance between the outcome variable (stunting) and the fractional rank in the socioeconomic distribution (wealth index) as follows:

$$
C=\frac{2}{\mu} C O V_{w}\left(y_{i}, R_{i}\right)
$$

Here, $y_{i}$ refers to the outcome of the $\mathrm{i}^{\text {th }}$ individual, $R_{i}$ is the fractional rank of the $\mathrm{i}^{\text {th }}$ ranked individual in the socioeconomic distribution, while $\mu$ is the weighted mean of $y$, and $C O V_{w}$ denotes the weighted covariance.

\section{Decomposition of inequalities}

To identify the contribution of each of the predictors to the observed socioeconomic inequality in stunting we decomposed the concentration index of stunting to reflect the proportional contributions of predictors, together with an unexplained residual component $(\varepsilon)$. For any linear additive regression model explaining outcome $(y)$, with a set of predictors $(k)$, their regression coefficients $\left(\beta_{k}\right)$, the intercept $(\alpha)$, the relative contributions of $X_{k}$ predictors and error term $(\varepsilon)[35,38]$ such as

$$
y=\alpha+\sum_{k} \beta_{k} X_{k}+\varepsilon
$$

the concentration index for y (i.e. C) can be written as follows: 


$$
C=\sum_{k}\left(\frac{\beta_{k} \bar{X}_{k}}{\mu}\right) C_{k}+\frac{G C_{\varepsilon}}{\mu}
$$

Equation (3) shows that the overall inequality in outcome has two components, a deterministic or 'explained' component and an 'unexplained' component; one which cannot be explained by systematic variation in the predictors across wealth groups. In the deterministic component $\beta_{k}$ is the coefficient from a regression of outcome on predictor $k, \bar{X}_{k}$ is the mean of predictor $X_{k}$, $\mu$ is the mean of $y$ and $C_{k}$ is the concentration index for predictor $X_{k}$ (defined analogously to $\mathrm{C}$ ). In the unexplained component, $G C_{\varepsilon}$ is the generalized concentration index for the error term $(\varepsilon)$. Using the explained component, we can calculate the contribution of each predictor to inequality by multiplying the outcome elasticity (impact each predictor has on the outcome) with respect to that predictor and its concentration index (degree of unequal distribution) i.e. $\left(\frac{\beta_{k} \bar{X}_{k}}{\mu}\right) C_{k}$.

Even if the contribution of a predictor is large, it will not have a large contribution to inequality, if it is equally distributed between the rich and the poor. Predictors that are more concentrated among the poor and associated with a higher probability of stunting, or those that are more prevalent among the rich and associated with a lower probability of stunting would lead to inequality. Thus, both the impact of the predictor on the outcome, as well as its distribution by economic status (given by concentration index) determines the contribution of predictors to total inequality. Next, the percentage contribution of each predictor can be estimated by dividing its absolute contribution by the concentration index of the outcome i.e. $\left(\frac{\beta_{k} \bar{X}_{k}}{\mu}\right) C_{k} / C$.

The decomposition method was first introduced for use with linear prediction models [38]. However, in our study the outcome variable is binary and thus requires non-linear statistical techniques. Of the two popular choices - the logit and the probit model that yield probabilities in the range $(0,1)$ and are fitted by maximum likelihood; we used the probit model which has also been used in another study [19]. Because the normal and logistic distributions are similar, the choice between a probit or a logit specification is not important in most cases [35].

$$
h_{i}=\alpha^{m}+\sum_{k} \beta_{k}^{m} X_{k i}+u_{i}
$$

In a probit model, using marginal or partial effects $(d h / d x)$, which gives the change in predicted probability associated with unit change in predictor variable, allows for dealing with discrete changes from 0 to 1 . Thus, this approximation of non-linear relationship using marginal effects restores the mechanism of the decomposition framework in eqs. (2) through (4) [39]. Equation (4) gives the linear approximation of the non-linear estimations, where $u_{i}$ indicates the error generated by the linear approximation used to obtain the marginal effects. This method has been used previously in analysis of health sector inequalities $[40,41]$. We calculated average marginal effects from predictions of probit model and a two-tailed $P$ value $<0.05$ was considered statistically significant. All the estimates take sampling weights into consideration. We used Stata $15.1^{\circ}$ for statistical analyses.

\section{Results}

\section{Socioeconomic inequalities}

Stunting has consistently declined in all wealth quintiles between 1996 and 2016. However, the reduction was relatively higher among the richer quintiles compared to the poorer ones. In 1996, stunting was $64.5 \%$ (95\% CI: 61.4 to 67.7 ) in the poorest (first) quintile and $39.8 \%$ (35.5 to 44.0 ) in the richest (fifth) quintile (Table 2, Fig. 1). By 2016, stunting dropped in Nepal to $49.2 \%$ (44.8 to 53.6 ) in the poorest quintile, $16.5 \%$ (11.7 to 21.3) in the richest quintile, and in between these outcomes in the middle quintiles. The average decline per year during this period was 0.8 percentage points in the poorest quintile compared to 1.2 percentage points in the richest quintile which was the highest rate of reduction among all wealth groups.

The largest absolute decline in stunting prevalence between 1996 and 2016 occurred in the richest quintile with 23.3 percentage points. The corresponding percentage decline between 1996 and 2016 was 58.5\% which took place at the rate of $4.3 \%$ per year (Table 2). As a result of the greater absolute decline in stunting in the richest quintile than in the poorest quintile, the difference between these quintiles increased from 24.7 in 1996 to 32.7 in 2016 (Table 2, Fig. 1). The relative disparity between the poorest and the richest groups has also increased; the ratio of stunting in the first quintile to fifth quintile was 1.6 in 1996 and 3.0 in 2016.

Figure 2 presents concentration curves for stunting in 1996 and 2016. In 1996, the concentration curve was consistently above the line of equality, which means stunting was disproportionately concentrated in poorer households. In 2016, the curve has shifted even further away from the line of equality, showing increase in degree of inequality over the years. In order to obtain zero inequality, it is necessary to redistribute $5.9 \%$ stunting (not stunted) in 1996 and 11\% in 2016 from the richer to the poorer half of the population. Here, we can reject the null of non-dominance at the five percentage level of significance using the less strict option within the test described in O'Donnell et al. [35]. This means the 2016 
Table 2 Trends and estimates for quintile-specific stunting in 1996, 2001, 2006, 2011 and 2016

\begin{tabular}{|c|c|c|c|c|c|c|c|c|c|}
\hline & \multicolumn{5}{|c|}{ Stunting ( $95 \%$ confidence intervals) } & \multicolumn{2}{|c|}{$\begin{array}{l}\text { Absolute decline in stunting } \\
\text { (percent points) }\end{array}$} & \multicolumn{2}{|c|}{$\begin{array}{l}\text { Percentage decline } \\
\text { in stunting (\%) }\end{array}$} \\
\hline & & & & & & $\begin{array}{l}\text { Average } \\
\text { decline per } \\
\text { year }\end{array}$ & $\begin{array}{l}\text { Total } \\
\text { decline }\end{array}$ & $\begin{array}{l}\text { Average } \\
\text { decline } \\
\text { per year }\end{array}$ & $\begin{array}{l}\text { Total } \\
\text { decline }\end{array}$ \\
\hline & 1996 & 2001 & 2006 & 2011 & 2016 & $1996-2016$ & 1996-2016 & 1996-2016 & 1996-2016 \\
\hline $\begin{array}{l}\text { First quintile } \\
\text { (poorest) }\end{array}$ & $\begin{array}{l}64.5 \\
(61.4 \text { to } 67.7)\end{array}$ & $\begin{array}{l}67.6 \\
(65.2 \text { to } 70.1)\end{array}$ & $\begin{array}{l}61.6 \\
(58.7 \text { to } 64.5)\end{array}$ & $\begin{array}{l}56 \\
\text { (51.7 to } 60.2)\end{array}$ & $\begin{array}{l}49.2 \\
(44.8 \text { to } 53.6)\end{array}$ & 0.8 & 15.3 & 1.3 & 23.7 \\
\hline Second quintile & $\begin{array}{l}61 \\
\text { (57.3 to } 64.7)\end{array}$ & $\begin{array}{l}61.3 \\
(58.4 \text { to } 64.1)\end{array}$ & $\begin{array}{l}54.9 \\
(51.3 \text { to } 58.4)\end{array}$ & $\begin{array}{l}45.7 \\
(40.4 \text { to } 51.0)\end{array}$ & $\begin{array}{l}38.7 \\
\text { (34.0 to } 43.3)\end{array}$ & 1.1 & 22.3 & 2.2 & 36.6 \\
\hline Third quintile & $\begin{array}{l}58.1 \\
(54.3 \text { to } 62.0)\end{array}$ & $\begin{array}{l}54.3 \\
(51.3 \text { to } 57.3)\end{array}$ & $\begin{array}{l}50.4 \\
(46.6 \text { to } 54.1)\end{array}$ & $\begin{array}{l}34.5 \\
(29.4 \text { to } 39.7)\end{array}$ & $\begin{array}{l}35.7 \\
\text { (31.1 to } 40.3)\end{array}$ & 1.1 & 22.4 & 2.4 & 38.6 \\
\hline Fourth quintile & $\begin{array}{l}52.2 \\
(48.4 \text { to } 55.9)\end{array}$ & $\begin{array}{l}53.1 \\
(50.0 \text { to } 56.1)\end{array}$ & $\begin{array}{l}39.8 \\
\text { (36.1 to } 43.4)\end{array}$ & $\begin{array}{l}30.5 \\
\text { (24.7 to } 36.3)\end{array}$ & $\begin{array}{l}32.4 \\
(27.5 \text { to } 37.4)\end{array}$ & 1.0 & 19.8 & 2.4 & 37.9 \\
\hline $\begin{array}{l}\text { Fifth quintile } \\
\text { (richest) }\end{array}$ & $\begin{array}{l}39.8 \\
(35.5 \text { to } 44.0)\end{array}$ & $\begin{array}{l}42.1 \\
(38.9 \text { to } 45.4)\end{array}$ & $\begin{array}{l}30.9 \\
(26.9 \text { to } 35.1)\end{array}$ & $\begin{array}{l}25.8 \\
\text { (20.1 to } 31.5)\end{array}$ & $\begin{array}{l}16.5 \\
\text { (11.7 to } 21.3)\end{array}$ & 1.2 & 23.3 & 4.3 & 58.5 \\
\hline Total stunting & $\begin{array}{l}56.6 \\
\text { (54.9 to } 58.2)\end{array}$ & $\begin{array}{l}57.2 \\
(55.9 \text { to } 58.5)\end{array}$ & $\begin{array}{l}49.3 \\
(47.7 \text { to } 50.9)\end{array}$ & $\begin{array}{l}40.5 \\
\text { (38.1 to } 42.9)\end{array}$ & $\begin{array}{l}35.8(33.7 \text { to } \\
38.0)\end{array}$ & 1.0 & 20.8 & 2.3 & 36.7 \\
\hline $\begin{array}{l}\text { Ratio of first to fifth } \\
\text { quintile stunting }\end{array}$ & 1.6 & 1.6 & 2.0 & 2.2 & 3.0 & & & & \\
\hline $\begin{array}{l}\text { Difference in first } \\
\text { and fifth quintile } \\
\text { stunting }\end{array}$ & 24.7 & 25.5 & 30.7 & 30.2 & 32.7 & & & & \\
\hline $\begin{array}{l}\text { Concentration index } \\
\text { (95\% confidence } \\
\text { intervals) }\end{array}$ & $\begin{array}{l}-0.078 \\
(-0.094 \\
\text { to }-0.061)\end{array}$ & $\begin{array}{l}-0.083 \\
(-0.095 \\
\text { to }-0.070)\end{array}$ & $\begin{array}{l}-0.125 \\
(-0.143 \\
\text { to }-0.108)\end{array}$ & $\begin{array}{l}-0.164 \\
(-0.194 \\
\text { to }-0.134)\end{array}$ & $\begin{array}{l}-0.147 \\
(-0.179 \\
\text { to }-0.114)\end{array}$ & & & & \\
\hline $\begin{array}{l}\text { Standard error of } \\
\text { concentration index }\end{array}$ & 0.008 & 0.006 & 0.009 & 0.015 & 0.017 & & & & \\
\hline $\begin{array}{l}\text { Normalized } \\
\text { concentration index }{ }^{\mathrm{a}}\end{array}$ & -0.178 & -0.193 & -0.247 & -0.276 & -0.228 & & & & \\
\hline Weighted N & 3703 & 6442 & 5258 & 2485 & 2421 & & & & \\
\hline
\end{tabular}

${ }^{a}$ Normalization of concentration index involves dividing the concentration index by (1 - proportion stunted)

concentration curve dominates (lies above) that of 1996 but the two curves overlap toward the bottom of the wealth distribution.

In addition, the concentration index increased (in absolute value) from -0.078 (95\% CI: -0.094 to -0.061$)$ in 1996 to -0.164 ( -0.194 to -0.134 ) in 2011 (Table 2, Fig. 3). It decreased slightly from 2011 to 2016 (-0.147, $95 \%$ CI: -0.179 to -0.114$)$. The negative values indicate that stunting was disproportionately concentrated in poorer households. We find that socioeconomic inequalities in stunting, as measured by concentration index, worsened from 1996 to 2011, however improved somewhat in 2016. The 'normalized' concentration indices show even stronger evidence of the burden of stunting being more concentrated among the poor (Table 2).

\section{Marginal effects of predictors}

In mothers having a higher BMI the chances of stunting were significantly reduced in 2016 (Normal, $P=0.042$ and Overweight/Obese, $P=0.003)$. Results were similar in 1996, but statistically non-significant (Table 3). Mothers with 'secondary and above' education had significantly lower probability $(P=0.020)$ of stunting in 1996. Although results were similar in 2016 i.e. higher education decreasing the chances of stunting, it was not statistically significant. Mothers with short height $(<145$ $\mathrm{cm})$ were significantly more likely $(P<0.001)$ to have stunted children both in 1996 and 2016 with higher effect in 2016.

Children aged 25-59 months had significantly higher chances $(P<0.001)$ of stunting and it did not change over the study period (Table 3$)$. Likewise, in $1996(P<0.001)$ as well as $2016(P=0.007)$, higher birth order was significantly associated with increased probability of stunting; effects were similar and were largest for children born fifth or later. Small (perceived) size of baby at birth had significantly higher probability of stunting in $1996(P<0.001)$ as well as $2016(P=0.039)$. Those of Janajati $(P<0.001)$, Newar $(P<0.001)$ and Brahmin/Chhetri $(P=0.002)$ origin were significantly less likely to be stunted in 1996, the effect being largest in Newar. In contrast, such effects were not significant in 2016. The upper two wealth quintiles had significant negative associations with probability of stunting in 1996 (Fourth, $P<0.001$ and Fifth, $P=0.001$ ); 

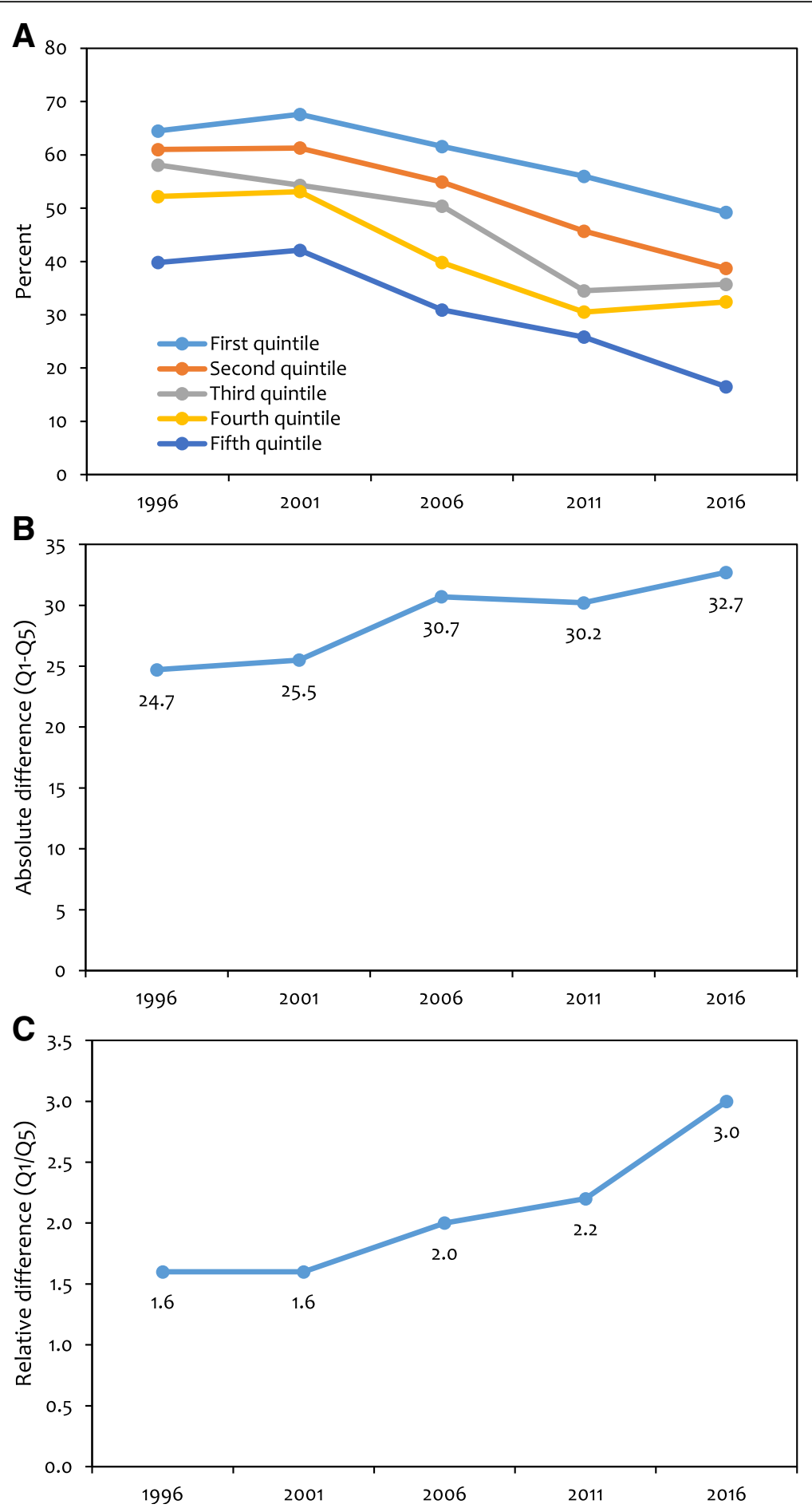

Fig. 1 Quintile-specific trends in stunting from 1996 to 2016. (a) Stunting prevalence (b) Absolute difference (Q1-Q5) (c) Relative difference (Q1/ Q5). The first quintile (Q1) is the 20\% poorest quintile and the fifth quintile (Q5) is the 20\% richest. (Weighted N: - 1996: 3703; 2001: 6442; 2006: 5258; 2011: 2485; 2016: 2421)

additionally, in 2016, the middle/third quintile also showed significant negative association $(P=0.002)$. In both years, largest effects were seen in the richest quintile.

\section{Decomposition of inequalities}

In Table 3 which presents decomposition analysis, the concentration index for stunting was -0.082 in 1996 


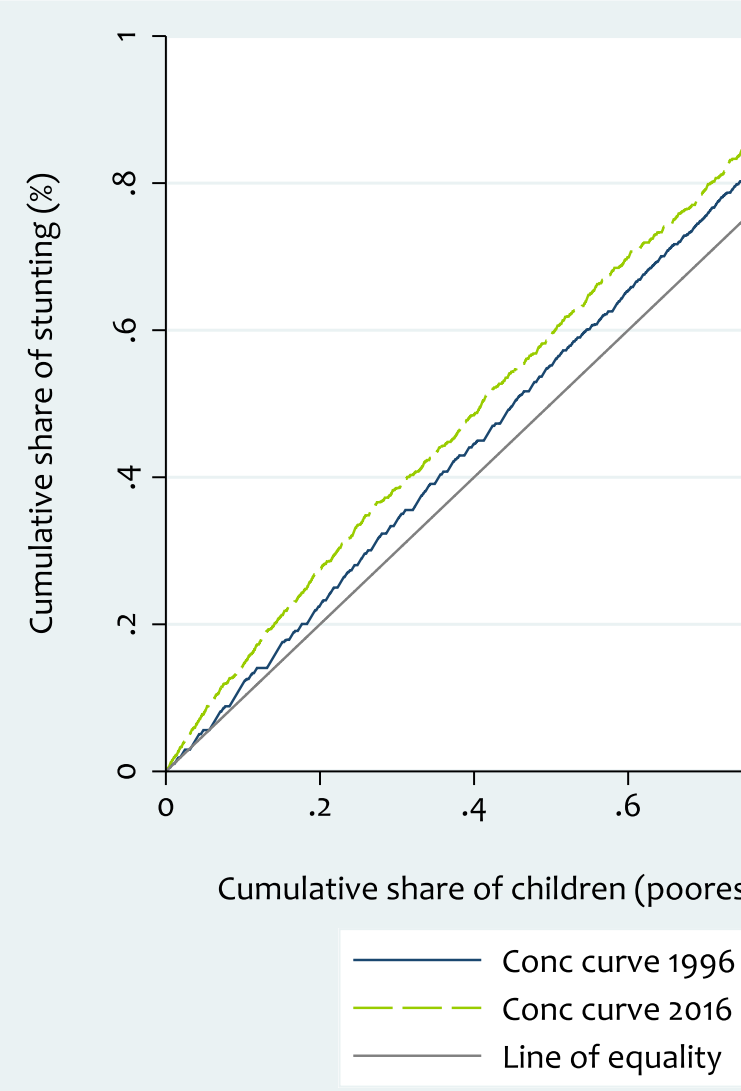

Fig. 2 Concentration curve for stunting, 1996 and 2016 (Weighted N: - 1996: 3703; 2016: 2421)

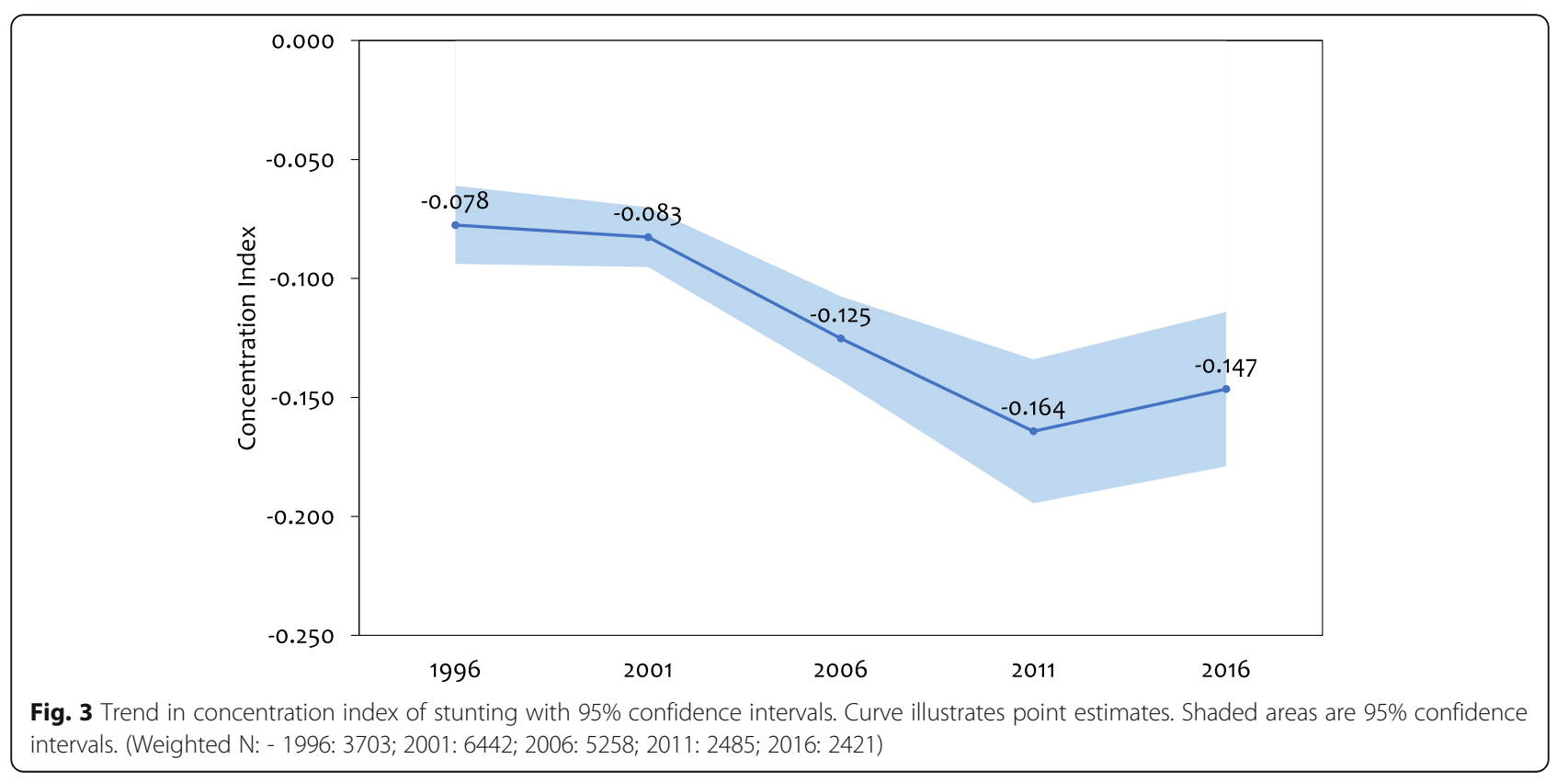




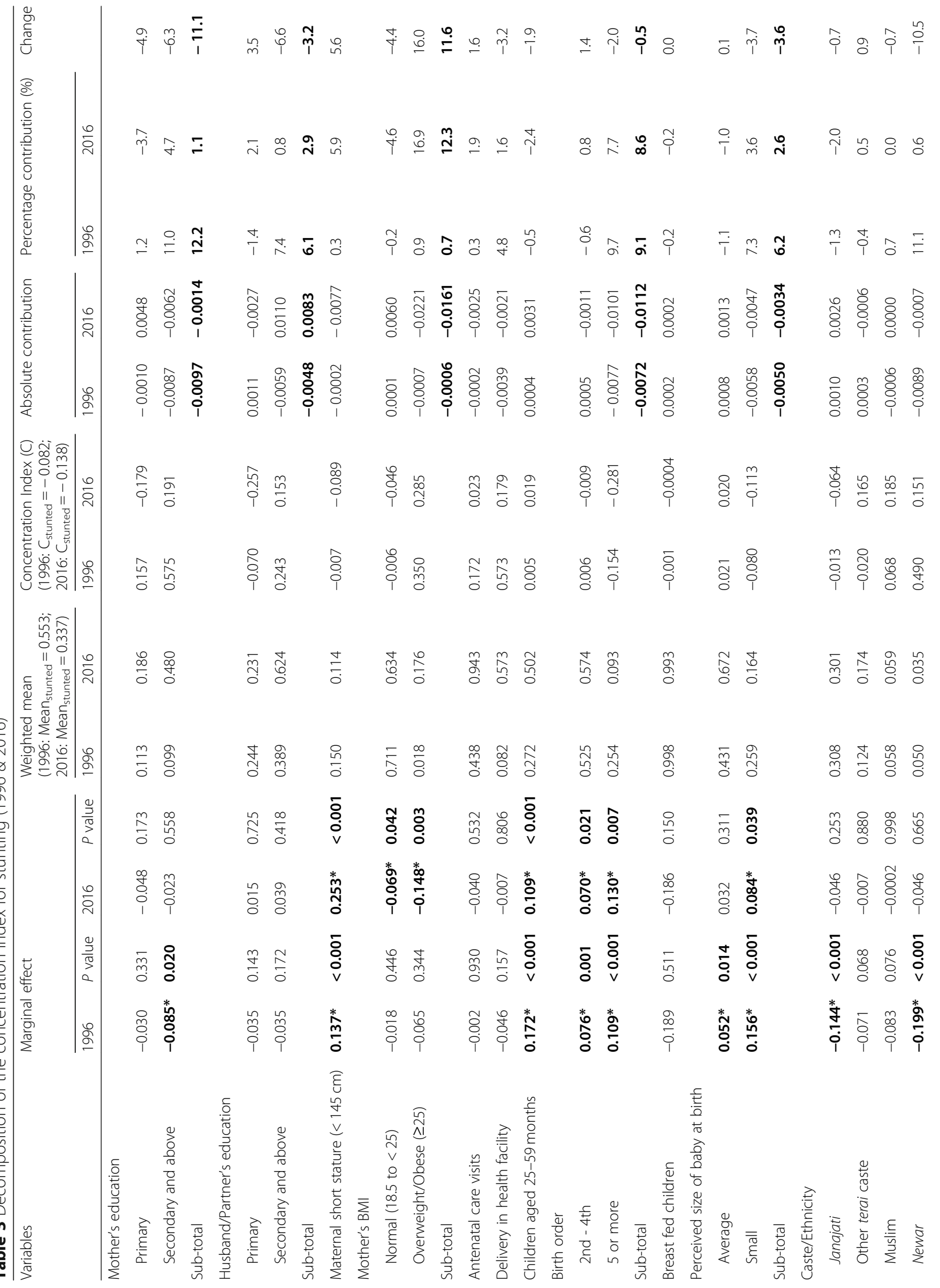




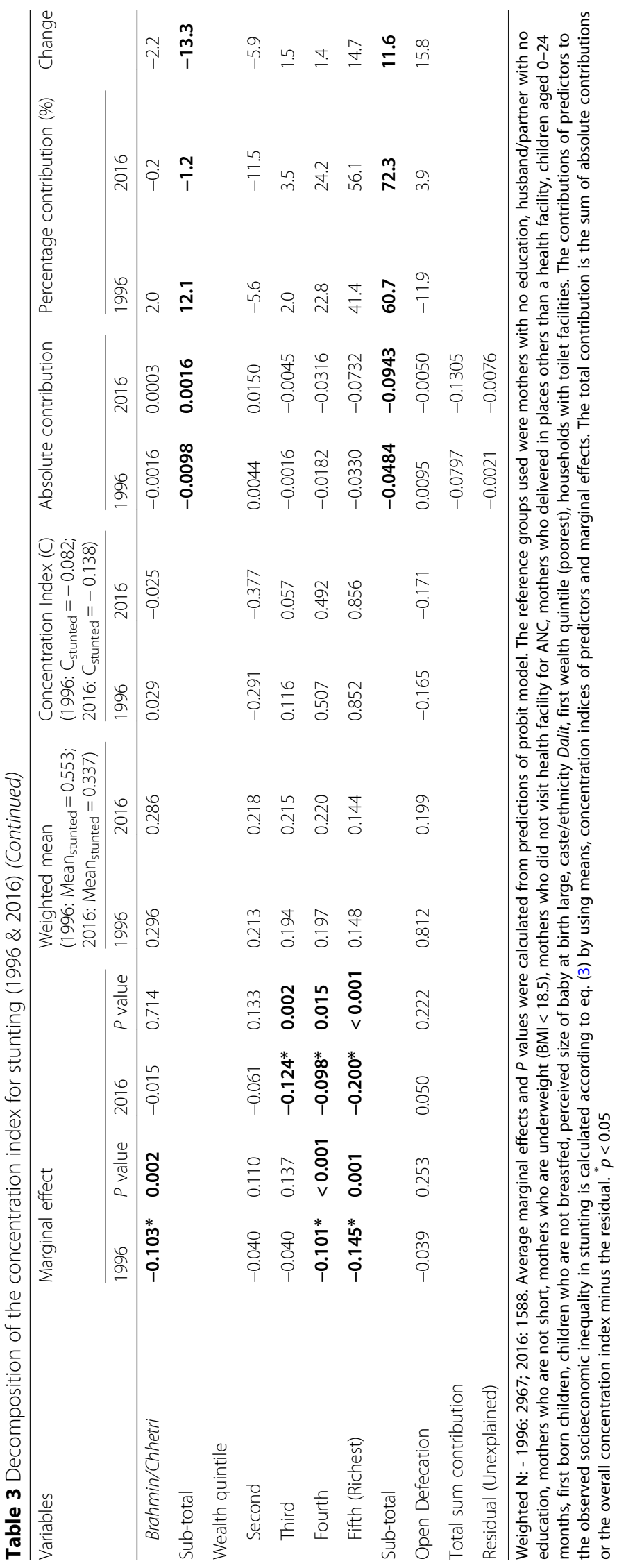


and -0.138 in 2016 (Weighted N: 1996-2967; 20161588), indicating that stunting was concentrated amongst the poor, more in 2016 than in 1996. The absolute contribution of each predictor was obtained by multiplying its marginal effect by its mean and concentration index, then dividing by the mean of stunting (0.553 in 1996 and 0.337 in 2016). For example, the contribution of being in the richest wealth quintile in 1996 can be computed as: Marginal effect $(-0.145)$ "Mean (0.148) "Concentration Index (0.852) divided by weighted mean of stunting $(0.553)=-0.0330$. Likewise, for 2016, $(-0.200) *(0.144) *(0.856) /(0.337)=-0.0732$. Positive (negative) contributions of predictors indicate that the total inequality would, ceteris paribus, be lower (higher) if that predictor had no impact on stunting (instead of that reflected in marginal effects) or was equally distributed across the socioeconomic spectrum (instead of concentrated, as mirrored in the concentration indices of predictors) [41]. The corresponding percentage contributions can be calculated by dividing the contribution of each predictor by the total (sum contribution) explained portion of the concentration index $(-0.0797$ in 1996 and -0.1305 in 2016), which is $=-0.0330 /-$ $0.0797=41.4 \%$ in 1996 and $-0.0732 /-0.1305=56.1 \%$ in 2016. Therefore, being in the richest wealth quintile contributed to $41.4 \%$ of the inequalities in stunting in 1996, which is lower than the contribution of 56.1\% in 2016.
Similarly, in Table 3, where overall stunting is concentrated amongst the poor (negative concentration index) we can interpret the contributions of individual predictors to the overall inequality as follows. Children born fifth or later (birth order) had an above average probability of stunting (positive marginal effect), were disproportionately concentrated in lower income groups (negative concentration index), and thus contributed -0.0077 or $9.7 \%$ in 1996 and -0.0101 or $7.7 \%$ in 2016 to the total observed inequality in stunting; a decrease in contribution of two percentage points. Since these contributions have the same sign as the overall concentration index, which indicates that stunting was concentrated amongst the poor, these indicate that children born fifth or later were a major pool of poor people with stunting. In perceived size of baby at birth, the 3.6\% contribution of babies born small in 2016 was lower than the $7.3 \%$ contribution estimated in 1996; a decrease in contribution of 3.7 percentage points. In the same way we can compare contributions across categories of a predictor. For example, in 2016 the contribution of babies born $2^{\text {nd }}-4^{\text {th }}$ in order was only $0.8 \%$; lower than that contributed by those born $5^{\text {th }}$ or later $(7.7 \%)$.

We can interpret a contribution with opposite sign to that on the overall concentration index in the following way. In 1996, children aged 25-59 months had

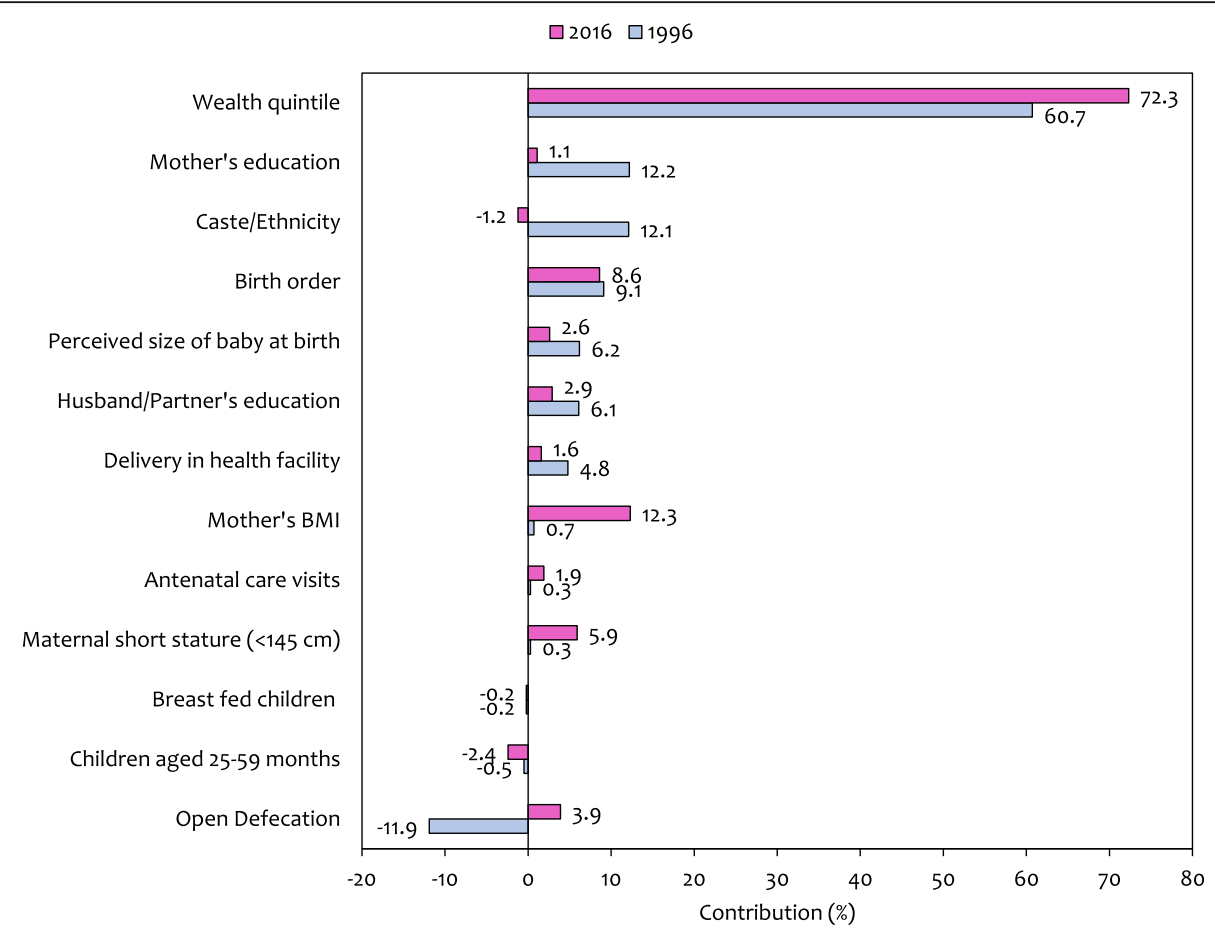

Fig. 4 The percentage contribution of predictors to the total inequality in stunting in Nepal in 1996 compared to 2016. (Weighted N: - 1996: 2967; 2016: 1588) 
a higher probability of stunting than children aged 0 24 months (the reference group) - a significant positive marginal effect of 0.172 . However, since they were disproportionately concentrated in the higher income group (positive concentration index of 0.005), their contribution of 0.0004 was in the opposite direction to the overall inequality observed.

Analysing caste/ethnicity in 1996 we find that there is negative association between being a Newar and stunting (negative marginal effect); and with Newar being a rich group (positive concentration index) results in being of Newar origin contributing -0.0089 , or $11.1 \%$, to the total inequality; which is higher than the contribution of just $0.6 \%$ in 2016; a decrease of 10.5 percentage points. In mother's education, a negative association between those with secondary level and above education and stunting (negative marginal effect) and their concentration among the richer households (positive concentration index), has led to higher education level of mothers contributing -0.0087 , or $11.0 \%$, to the total inequality. In 2016, this contribution decreased by 6.3 percentage points and was just $4.7 \%$.

Maternal short stature was positively associated with stunting (positive marginal effect), and as those with short height were disproportionately poor (negative concentration index) they contributed -0.0002 , or $0.3 \%$, in 1996 and 0.0077 , or $5.9 \%$, in 2016; an increase in contribution of 5.6 percentage points to the total inequality. A higher mother's BMI was negatively associated with stunting (negative marginal effect), and since those who were overweight/obese were disproportionately rich (positive concentration index) they contributed -0.0007 , or $0.9 \%$, in 1996 and -0.0221 , or $16.9 \%$, in 2016; an increase in contribution of 16 percentage points to the total inequality. In the same way we can interpret other decomposition results.

We can also compare the overall contribution of a particular predictor by summing up contributions across its categories (reflected in sub-total, Table 3 and Fig. 4). In 1996, the major contributors to the observed socioeconomic inequalities in stunting were: wealth $(60.7 \%)$, mother's education (12.2\%), caste/ethnicity (12.1\%) and birth order (9.1\%). ANC visits, maternal short stature and mother's BMI played a less important role in terms of inequalities. In 2016, wealth (72.3\%), mother's BMI $(12.3 \%)$ and birth order (8.6\%) were the major contributors while mother's education, delivery in health facility and ANC visits did not contribute considerably. Wealth was the biggest contributor to inequality in stunting and its contribution has increased by 11.6 percentage points between 1996 and 2016. The contribution of caste/ethnicity and mother's education has decreased, while that of mother's BMI has increased. The contribution of birth order to the total inequality in stunting has more or less remained constant.

\section{Discussion}

From 1996 to 2016, Nepal's political and economic climate was marred by an armed conflict, unstable governments, a massive earthquake with subsequent economic blockade by its neighbour, and transition to a new federal governance structure. In spite of such adversities, on an average, Nepal made remarkable ground in maternal and child nutrition indicators [30, 32]. However, with national averages we cannot identify those who are being left behind. Thus, using data from periodic surveys conducted during the 20-year time period, we analysed trends and predictors of inequalities in chronic malnutrition, stunting. Our analysis revealed widening disparity in stunting between the poorest and richest households both in absolute and relative terms. The better off have experienced larger and faster decline in stunting compared to the least affluent. Household economic status was the biggest contributor to inequality in stunting and its contribution has increased.

Although stunting has decreased in all wealth quintiles, the absolute gap between the poorest and richest households has increased, with consistently lower (higher) prevalence in richest (poorest) group. The absolute decline in stunting in the richest households was nearly $50 \%$ higher than those in the poorest households. Usually, as coverage of health interventions increase, the rich selectively benefit first, then only the poorest will lag behind all other groups $[42,43]$. This was evident in our study where absolute disparities were smaller when stunting prevalence was high - possibly because most of the population, including the richest households, had inadequate access to nutrition interventions. But as stunting declined over time, largely driven by the faster decline among the richest households, stunting persisted in the poor with relatively lower rates of decline. Likewise, the relative difference between the poorest and richest stunting prevalence has also increased. By 2016 three times more children were stunted in the poorest quintile as compared with those in the richest quintile. This is expected when prevalence at the national level is decreasing. As stunting decline among the poor is outpaced by that in the rich, the absolute differences become higher which leads to higher ratios or relative inequalities.

The concentration curve and index analyses also revealed pro-rich improvements which have become more pronounced over time. Other studies from the region show similar patterns where stunting is declining on one hand while socioeconomic inequality is increasing on the other $[18,19,44]$. A lack of association between the rate of decline in stunting and improvement in equity was also reported in a multi-country analysis of survey data [45]. This unwanted trend in light of the government's explicit commitment to enhance equity [21, $22,46]$ questions the strategies and also the 
effectiveness of nutrition interventions. While government policies and programs are pro-poor and pro-inclusive, these results provide a strong case that stunting is distributed unequally across different socioeconomic subgroups in the population.

From decomposition analysis it is clear that most of the inequality was due to household economic status both in 1996 and 2016. In Nepal, improved access to healthcare, improvements in sanitation mainly use of toilets, improvements in (mother's) education and particularly wealth accumulation have been identified as the key drivers of reduction in undernutrition [30, 32]. It is fair to say that nutrition sensitive interventions that address the underlying determinants of nutrition, including poverty and that draw on complementary sectors such as agriculture, health, social protection, early child development, education, and water and sanitation $[47,48]$ are more important for addressing inequities in stunting. Social safety nets that raise income among vulnerable groups and make them resilient to economic shocks are needed [48]. By redistributing income to the poorest and most vulnerable, they not only have an immediate impact on poverty and inequality [49] but also increase use of health and education services [50]. In this regard, there is much to learn from Bangladesh where pro-poor and women-focused investments in health and social development have contributed to equity gains in child survival [51]. One intervention that stands out is women's microcredit that aimed to reduce poverty by providing poor families with access to small collateral-free loans. They targeted the ultra-poor women, encouraging economic and social empowerment and has had various positive effect on health outcomes [51]. Nevertheless, given the limited health system capacity, we need to first better understand the cost effectiveness and desirability of social safety net programs in Nepal, as in the past they have been found to have unintended negative consequences [52].

Similar studies in the region have noted mother's education to be a prime contributor to inequalities in stunting $[18,19,53]$. Better education will not only contribute to higher household income but may also result in improved health knowledge, greater access to and use of health services, healthier feeding habits and enhanced decision making power within the household $[54,55]$. In Nepal, more girls are getting education than ever before. The ratio of girls to boys in primary education increased from 0.56 in 1990 to 1.09 in 2015 [56]. This is a result of efforts to increase public expenditure in education. It started in the early 1990s and was provided further momentum in 2001 when the education for all national plan of action was adopted that brought gender equality and social inclusion to the forefront [30]. As a result, not only rich but poor women may also be getting educated, thus reducing the contribution of mother's education to overall inequality.

With 125 caste/ethnic groups [57], Nepal's population is diverse in caste/ethnicity. The contribution of caste/ ethnicity to inequality in stunting has decreased, largely due to reduction in contribution of Newar. Stunting in Newar has become lesser pro-rich in 2016 compared to 1996, which means inequality has decreased. In general, Newar have a better health status compared to others. In 2016, they had the highest levels of institutional delivery, demand satisfied for family planning and children fully immunized; and lowest prevalence of anaemia and thinness $(\mathrm{BMI}<18.5)$ among women. They also had the lowest rates of under-five and neonatal mortality rate and total fertility rate. In contrast, Muslim, other Terai caste and Dalit had relatively lower levels of service utilization and poorer health outcomes [58]. During the period of notable poverty reduction in Nepal between 1995 and 2010 when national poverty rates fell from 64 to $25 \%$ [59]; among all caste/ethnic groups, Newar consistently had lowest poverty rates, while Dalit stood on the bottommost end of the spectrum $[60,61]$.

The contribution of mother's BMI to inequality has increased, owing to bigger contribution of overweight/ obese mothers to inequality. Both in 1996 and 2016, stunting among children of overweight/obese mothers was disproportionately concentrated in richer households. In fact, a previous study has shown that compared to poorest households, the odds of being overweight and obese were higher among adult women belonging to the richest households [62]. However, compared to 1996, not only there was significant negative association between overweight/obese mothers with probability of stunting but also the proportion of mothers who were overweight/obese increased from just 1.8 to $17.6 \%$ in 2016. Other studies based on DHS data also show increasing prevalence of overweight and obesity among women of reproductive age $[63,64]$. The rich poor differentials and growing prevalence of overweight/obesity has made mother's BMI a major contributor to inequality. These are indications of changing lifestyle and highlights the need to adjust the existing strategies so that multiple forms of malnutrition can be addressed.

Similar to our results, a previous study reported significant association between higher birth order and stunting among children in Nepal [13]. Additionally, height-for-age z-scores, was also found to have significant negative association with higher fertility [65]. As opposed to 1996, the proportion of children born fifth or later has decreased in 2016, from 25.4 to $9.3 \%$ in our analysis; but this effect has been nullified by the increase in inequality - stunting concentration becoming even higher among the poor. In Nepal, even though women 
are having fewer children than before, the decline in total fertility rate in the poorer households is relatively slower compared to that in the richer households. In 2016, the total fertility rate was highest in the poorest wealth quintile at 3.2 compared to 1.6 in the richest quintile [10], which explains the negative shift of the concentration index in 2016 with regards to birth order. This is possibly the reason why contributions of birth order to inequality has remained similar over the years. A higher fertility not only has adverse consequences on mother's health, but also affects the child's birth weight and the mother's ability to feed and care for her child [18], which are possible pathways to stunting. This highlights the need to further improve family planning practices among the poor.

Maternal short stature has intergenerational effects as measured by height of the mother on stunting [66]. A shorter height may lead to intrauterine growth retardation [67] and low birth weight [68], causing mortality and impaired child growth [2]. With higher positive effect and pro poor distribution, the contribution of maternal short stature to inequality has increased. Similarly, the concentration of small size of the baby at birth (perceived) has increased among the poor but due to its reduced positive effect on stunting as well as reduced prevalence, its overall contribution to inequality has decreased. A generation of poor women who were stunted as children may have given birth to children with similar impaired growth. Thus, it is crucial to formulate strategies that incorporate a life cycle approach to address nutrition issues during critical periods from conception to adulthood. Integration of nutrition counselling across maternal and child health and family planning interventions is also equally important. However, any new interventions and/or changes will need to be reflected at all levels of the government, especially at the local level, where services are delivered.

Improvements in availability of health care services have been identified to be among the key drivers of reduction in undernutrition in Nepal [30, 32, 65]. We examined the contributions of ANC visits and institutional deliveries which have reduced overtime and together accounted for only $3.5 \%$ of inequality in 2016 . Utilization of these services has improved remarkably over the years. But what is even more noteworthy is the reduction in stunting inequality in these groups of mothers as indicated by the large shift of concentration index towards the null. Yet still the quality of ANC services is a concern that threatens these gains made. Only 17\% of health facilities in Nepal offered high quality ANC services in 2015 [69]. Poor-quality care is now a bigger barrier than insufficient access in countries like Nepal where multi stakeholder commitment is critical for quality improvements [70].
While interpreting results, the following caveats will need to be considered. First, although decomposition of concentration index helps identify factors that potentially contribute to socioeconomic inequality, it should not be interpreted as causal. Second, some important variables deemed to have association with stunting but not measured during 1996 survey were omitted. Third, analysis of dichotomous rather than continuous variables arguably weakens the power of statistical tests [71] but in exchange for easy interpretation and presentation of results we preferred the former. Besides, in case of stunting the cut off points are standardized and recognized world over and the sample sizes are large enough to greatly reduce this concern. In a previous study, conclusions did not change radically when height-for-age $\mathrm{z}$-scores were used as outcome instead of stunting [19]. Fourth, the use of wealth indices for the measurement of socioeconomic position in low income countries is criticized for being sensitive to choice of assets and for not reflecting short term economic shocks [72] and food affordability [31]. However, in absence of direct measurements of household wealth, such asset based index is a good proxy for household socioeconomic status. Fifth, the design of the 1996 and 2016 NDHS may not match completely but since we did not conduct pooled analysis, the estimates from respective surveys stand on their own and proportions should be comparable without much concern.

By applying standard analytical methods our results shed much needed light on the unequal progress in stunting decline in Nepal and has several implications. Nutrition sensitive interventions delivered via a multi-sectoral approach, including increasing overall investment in health and education is key. Increasing coverage of nutrition specific interventions using a life cycle approach in groups that are being left behind may address intergenerational stunting. Although recent efforts for policy coherence across the sectors [22] and rolling out of community level nutrition programmes is commendable; current strategies require targeted approach to address inequalities. By enhancing outreach services and strengthening the community system of service delivery with a focus on poor, disadvantaged and marginalized groups, coverage could be improved across all segments of the population. Efforts for poverty alleviation should go hand in hand with direct investments for reduction of undernutrition primarily in the poorest segments of the population. It is necessary to tackle structural factors that cause unequal wealth distribution through social protection programmes. They can also serve as a delivery platform for nutrition-specific interventions, potentially increasing their scale, coverage and effectiveness.

With the current average annual rate of reduction Nepal will not achieve the World Health Assembly's 
target to reduce stunting to $24.3 \%$ by 2025 [22] which will in turn offset its course towards SDG 2030 target as well. Interventions should be targeted at the subnational level where the factors causing inequalities are rife. The mountain zone [73], Karnali province and Province 2 [74] not only have relatively higher rates of poverty but also lower levels of education attainment among women and higher total fertility rate [10]. Within these regions, rural areas and communities that suffer higher levels of deprivation should be prioritized to reduce inequalities in stunting. In doing so, leadership of the local governments will be critical in the new federal governance structure. The focus should be on community based primary care approaches using community health workers and volunteers who in the past have successfully contributed to reducing equity gaps and improving access [75].

\section{Conclusions}

Despite remarkable improvements in average stunting over the past two decades, substantial socioeconomic inequalities in stunting exists in Nepal. Not only health system functions such as controlling fertility and improving maternal health but also factors beyond the scope of health authorities and care delivery system such as asset-based wealth distribution and education are at play in determining inequalities. In the past two decades, the better off segments of the population have experienced larger and faster decline in stunting compared to the least affluent and contribution of household wealth to inequalities has increased. Policy interventions that are tailored to inequality patterns, which reach the most disadvantaged and vulnerable groups, might help to change these trends. Multi-sectoral efforts are needed to target nutrition specific and nutrition sensitive programs including social protection for the poor. Political commitments need to be translated in to large scale programs. Nevertheless, for targeting priority populations, subnational information might be needed, which is an area for future studies to delve into.

\section{Endnotes}

${ }^{1}$ Topographically, Nepal is divided in to three distinct ecological belts along a south-to-north transect: Terai (or plains) constitutes 23\%, Hill constitutes $42 \%$ and Mountain constitutes $35 \%$ of total land. According to the latest national population census [57], 50\% of the population live in the terai, about $42 \%$ live in the hills and only about $7 \%$ live in the mountains. Because of the harsh terrain, transportation and communication facilities are very limited in the mountain zone.

${ }^{2}$ The new constitution of Nepal which came into effect on September 2015, restructured the country in to a federal democratic republic governed with three levels of government: a federal level, seven provinces and 753 local governments. The seven provinces are (starting from the East): Province 1, Province 2, Province 3, Gandaki Province, Province 5, Karnali Province and Sudur Paschim Province. Province 1, 2, 3 and 5 are yet to be named.

${ }^{3}$ Caste/Ethnicity groups as recoded by NDHS: Hill Brahmin, Hill Chhetri, Terai Brahmin/Chhetri, Other Terai caste, Hill Dalit, Terai Dalit, Newar, Hill Janajati, Terai Janajati, Muslim, Other.

\section{Abbreviations}

ANC: Antenatal Care; BMI: Body Mass Index; C: Concentration Index; NDHS: Nepal Demographic and Health Survey; NFHS: Nepal Family Health Survey; SD: Standard Deviation; SDG: Sustainable Development Goals; WASH: Water, Sanitation and Hygiene; WHO: World Health Organization

\section{Acknowledgements}

We would like to thank Nissim Raj Angdembay for reviewing the manuscript for language corrections. We are also grateful to the DHS program for providing the datasets for analysis.

\section{Funding}

Not applicable.

\section{Availability of data and materials}

The datasets analysed during the current study are available in the DHS repository, https://dhsprogram.com/data/available-datasets.cfm

\section{Authors' contributions}

MRA and BPD conceived and designed the study. MRA performed statistical analysis and drafted the manuscript. BPD and KB helped analysing the data and draft the manuscript. SK and BPD helped discuss the results. MRA made critical revisions and finalized the manuscript. All authors read and approved the final manuscript.

Ethics approval and consent to participate

Not applicable since the study uses secondary data from the NDHS series.

Consent for publication

Not applicable.

Competing interests

The authors declare that they have no competing interests.

\section{Publisher's Note}

Springer Nature remains neutral with regard to jurisdictional claims in published maps and institutional affiliations.

\section{Author details}

${ }^{1}$ HERD International, Thapathali-11, Kathmandu, Nepal. ${ }^{2}$ Social Development and Promotion Centre, Sanepa, Lalitpur, Nepal. ${ }^{3}$ South Asian Infant Feeding Research Network - Nepal, Kathmandu, Nepal.

Received: 24 October 2018 Accepted: 25 February 2019

Published online: 05 March 2019

\section{References}

1. World Health Organization. Nutrition Landscape Information System. Geneva: Switzerland World Health Organization; 2010.

2. Black RE, Allen LH, Bhutta ZA, Caulfield LE, de Onis M, Ezzati M, Mathers $C$, Rivera J. Maternal and child undernutrition: global and regional exposures and health consequences. Lancet. 2008:371:243-60.

3. Victora CG, Adair L, Fall C, Hallal PC, Martorell R, Richter L, Sachdev HS Maternal and child undernutrition: consequences for adult health and human capital. Lancet. 2008;371:340-57. 
4. National Planning Commission [Government of Nepal]. Multi-sector Nutrition Plan I (2013-2017). Kathmandu: National Planning Commission. p. 2012.

5. United Nations Children's Fund, World Health Organization, World Bank Group. Levels and trends in child malnutrition: Key findings of the 2018 Edition of the Joint Child Malnutrition Estimates. p. 2018.

6. World Health Organization. Reducing stunting in children: equity considerations for achieving the global nutrition targets 2025. Geneva: World Health Organization; 2018

7. Ministry of Health [Nepal], New ERA, ORC Macro. Nepal Demographic and Health Survey 2001. Calverton, Maryland, USA: Family Health Division, Ministry of Health; New ERA; and ORC Macro; 2002.

8. Ministry of Health and Population (MOHP) [Nepal], New ERA, ICF International Inc. Nepal Demographic and Health Survey 2011. Kathmandu: Ministry of Health and Population, New ERA, and ICF International, Calverton, Maryland; 2012.

9. Ministry of Health and Population (MOHP) [Nepal], New ERA, Macro International Inc. Nepal Demographic and Health Survey 2006. Kathmandu: Ministry of Health and Population, New ERA, and Macro International Inc; 2007.

10. Ministry of Health Nepal, New ERA, ICF. Nepal Demographic and Health Survey 2016, Kathmandu: Ministry of Health, Nepal. p. 2017

11. Pradhan A, Aryal RH, Regmi G, Ban B, Govindaswamy P. Nepal Family Health Survey 1996. Kathmandu, Nepal and Calverton, Maryland: Ministry of Health [Nepal], New ERA, and Macro International Inc; 1997.

12. de Onis M, Branca F. Childhood stunting: a global perspective. Maternal \& Child Nutrition. 2016;12:12-26.

13. Tiwari R, Ausman LM, Agho KE. Determinants of stunting and severe stunting among under-fives: evidence from the 2011 Nepal demographic and health survey. BMC Pediatr. 2014;14:239.

14. Corsi DJ, Mejía-Guevara I, Subramanian SV. Risk factors for chronic undernutrition among children in India: estimating relative importance, population attributable risk and fractions. Soc Sci Med. 2016;157:165-85

15. Devkota MD, Adhikari RK, Upreti SR. Stunting in Nepal: looking back, looking ahead. Maternal \& Child Nutrition. 2016;12:257-9.

16. Krishna A, Mejia-Guevara I, McGovern M. Trends in inequalities in child stunting in South Asia; 2017.

17. Hangoma P, Aakvik A, Robberstad B. Explaining changes in child health inequality in the run up to the 2015 millennium development goals (MDGs): the case of Zambia. PLoS One. 2017;12:e0170995

18. Huda TM, Hayes A, El Arifeen S, Dibley MJ. Social determinants of inequalities in child undernutrition in Bangladesh: a decomposition analysis. Matern Child Nutr. 2018;14

19. Rabbani A, Khan A, Yusuf S, Adams A. Trends and determinants of inequities in childhood stunting in Bangladesh from 1996/7 to 2014. Int J Equity Health. 2016:15:186.

20. United Nations. Transforming our world: the 2030 agenda for sustainable development. New York: United Nations; 2015

21. Ministry of Health and Population [Government of Nepal]: Nepal Health Sector Strategy 2015-2020. Kathmandu: Ministry of Health and Population 2015.

22. National Planning Commission [Government of Nepal]. Multi-sector Nutrition Plan II (2018-2022). Kathmandu: National Planning Commission. p. 2017

23. World Health Organization (WHO) Multicentre Growth Reference Study Group. WHO child growth standards: length/height-for-age, weight-for-age, weight-for-length, weight-for-height and body mass index-for-age: methods and development. Geneva: World Health Organization; 2006.

24. World Health Organization. Nutrition landscape information system (NLIS) country profile indicators: interpretation guide. Geneva: World Health Organization; 2010

25. Stewart $\mathrm{CP}$, lannotti L, Dewey KG, Michaelsen KF, Onyango AW. Contextualising complementary feeding in a broader framework for stunting prevention. Matern Child Nutr. 2013;9(Suppl 2):27-45.

26. Solar O, Irwin A. A conceptual framework for action on the social determinants of health. Social determinants of health discussion paper 2 (policy and practice). Geneva: World Health Organization; 2011.

27. Pandey JP, Dhakal MR, Karki S, Poudel P, Pradhan MS. Maternal and child health in Nepal: the effects of caste, ethnicity, and regional identity: further analysis of the 2011 Nepal demographic and health survey. Nepal Ministry of Health and Population, New ERA, and ICF International: Calverton, Maryland, USA; 2013

28. United States Agency for International Development [Global Health Technical Assistance Project]. In: Adhikari RK, editor. Food utilization practices, beliefs and taboos in Nepal: An overview. Washington, DC: QED Group, LLC, with CAMRIS International and Social \& Scientific Systems, Inc; 2010.

29. Na M, Aguayo VM, Arimond M, Dahal P, Lamichhane B, Pokharel R, Chitekwe S, Stewart CP. Trends and predictors of appropriate complementary feeding practices in Nepal: An analysis of national household survey data collected between 2001 and 2014. Matern Child Nutr. 2018;14 Suppl 4:e12564

30. Cunningham K, Headey D, Singh A, Karmacharya C, Pandey Rana P. Maternal and child nutrition in Nepal: examining drivers of progress from the mid-1990s to. Global Food Security. 2010s;13:30-7.

31. Headey D. Developmental drivers of nutritional change: a cross-country analysis. World Dev. 2013:42:76-88.

32. Headey DD, Hoddinott J. Understanding the rapid reduction of undernutrition in Nepal, 2001-2011. PLoS One. 2015;10:e0145738.

33. Hong R, Banta JE, Betancourt JA. Relationship between household wealth inequality and chronic childhood under-nutrition in Bangladesh. Int J Equity Health. 2006;5:15.

34. Houweling TA, Kunst AE, Huisman M, Mackenbach JP. Using relative and absolute measures for monitoring health inequalities: experiences from cross-national analyses on maternal and child health. Int J Equity Health. 2007;6:15.

35. O'Donnell O, Doorslaer EV, Wagstaff A, Lindelow M. Analyzing health equity using household survey data: a guide to techniques and their implementation. Washington, DC: World Bank Publications; 2008.

36. Koolman X, van Doorslaer $\mathrm{E}$. On the interpretation of a concentration index of inequality. Health Econ. 2004;13:649-56.

37. Wagstaff $A$. The bounds of the concentration index when the variable of interest is binary, with an application to immunization inequality. Health Econ. 2005:14:429-32.

38. Wagstaff A, van Doorslaer E, Watanabe N. On decomposing the causes of health sector inequalities with an application to malnutrition inequalities in Vietnam. J Econ. 2003;112:207-23.

39. van Doorslaer E, Koolman X, Jones AM. Explaining income-related inequalities in doctor utilisation in Europe. Health Econ. 2004;13:629-47.

40. Sozmen K, Baydur H, Simsek H, Unal B. Decomposing socioeconomic inequalities in self assessed health in Turkey. Int J Equity Health. 2012;11:73.

41. Yiengprugsawan V, Lim LL, Carmichael GA, Sidorenko A, Sleigh AC. Measuring and decomposing inequity in self-reported morbidity and selfassessed health in Thailand. Int J Equity Health. 2007;6:23.

42. Victora CG, Joseph G, Silva ICM, Maia FS, Vaughan JP, Barros FC, Barros AJD. The inverse equity hypothesis: analyses of institutional deliveries in 286 National Surveys. Am J Public Health. 2018:108:464-71.

43. Victora CG, Vaughan JP, Barros FC, Silva AC, Tomasi E. Explaining trends in inequities: evidence from Brazilian child health studies. Lancet. 2000;356: 1093-8.

44. Subramanyam MA, Kawachi I, Berkman LF, Subramanian SV. Socioeconomic inequalities in childhood undernutrition in India: analyzing trends between 1992 and 2005. PLoS One. 2010:5:e11392.

45. Restrepo-Mendez MC, Barros AJ, Black RE, Victora CG. Time trends in socioeconomic inequalities in stunting prevalence: analyses of repeated national surveys. Public Health Nutr. 2015;18:2097-104

46. National Planning Commission [Government of Nepal]: Fourteen Development Plan (2016/17-2018/19) Kathmandu, Nepal; 2016.

47. Black RE, Victora CG, Walker SP, Bhutta ZA, Christian P, de Onis M, Ezzati M, Grantham-McGregor S, Katz J, Martorell R, Uauy R. Maternal and child undernutrition and overweight in low-income and middle-income countries. Lancet. 2013;382:427-51.

48. Ruel MT, Alderman $\mathrm{H}$. Nutrition-sensitive interventions and programmes: how can they help to accelerate progress in improving maternal and child nutrition? Lancet. 2013;382:536-51.

49. Grosh M, Del Ninno C, Tesliuc E, Ouerghi A. For protection and promotion: the design and implementation of eff ective safety nets. Washington, DC: World Bank; 2008

50. Lagarde M, Haines A, Palmer N. Conditional cash transfers for improving uptake of health interventions in low- and middle-income countries: a systematic review. Jama. 2007;298:1900-10. 
51. Adams AM, Rabbani A, Ahmed S, Mahmood SS, Al-Sabir A, Rashid SF, Evans TG. Explaining equity gains in child survival in Bangladesh: scale, speed, and selectivity in health and development. Lancet. 2013;382:2027-37.

52. Leroy JL, Gadsden P, Rodriguez-Ramirez S, de Cossio TG. Cash and in-kind transfers in poor rural communities in Mexico increase household fruit, vegetable, and micronutrient consumption but also lead to excess energy consumption. J Nutr. 2010;140:612-7.

53. Kumar A, Kumari D, Singh A. Increasing socioeconomic inequality in childhood undernutrition in urban India: trends between 1992-93, 1998-99 and 2005-06. Health Policy Plan. 2015;30:1003-16.

54. Aslam M, Kingdon GG. Parental education and child health-understanding the pathways of impact in Pakistan. World Dev. 2012;40:2014-32.

55. Miller JE, Rodgers W. Mother's education and children's nutritional status: new evidence from Cambodia. Asian Development Review. 2009;26:131-65.

56. National Planning Commission [Government of Nepal]. Nepal and the Millennium Development Goals: Final Status Report 2000-2015, Kathmandu: National Planning Commission. p. 2016.

57. Central Bureau of Statistics [Nepal]. National Population and Housing Census 2011 (National Report). vol. 1. Kathmandu: National Planning Commission Secretariat, Central Bureau of Statistics; 2012.

58. Ministry of Health and Population [Nepal]. Mind the gap: Policy brief. Kathmandu: Ministry of Health and Population; 2018.

59. Uematsu H, Shidiq AR, Tiwari S. Trends and Drivers of Poverty Reduction in Nepal: A Historical Perspective: World Bank Group [Poverty and Equity Global Practice Group]; 2016.

60. Lawyers' Association for Human Rights of Nepalese Indigenous Peoples (LAHURNIP), The International Work Group for Indigenous Affairs (IWGIA). A study on the Socio-Economic Status of Indigeneous Peoples in Nepal. Kathmandu: LAHURNIP and IWGIA; 2014.

61. DFID Nepal, The World Bank. "Unequal citizens" gender, caste and ethnic exclusion in Nepal, summary. DFID Nepal and The World Bank: Kathmandu; 2006.

62. Bishwajit G. Household wealth status and overweight and obesity among adult women in Bangladesh and Nepal. Obes Sci Pract. 2017;3:185-92.

63. Amugsi DA, Dimbuene ZT, Mberu B, Muthuri S, Ezeh AC. Prevalence and time trends in overweight and obesity among urban women: an analysis of demographic and health surveys data from 24 African countries, 1991-2014. BMJ Open. 2017:7:e017344.

64. Chowdhury MAB, Adnan MM, Hassan MZ. Trends, prevalence and risk factors of overweight and obesity among women of reproductive age in Bangladesh: a pooled analysis of five national cross-sectional surveys. BMJ Open. 2018;8:e018468.

65. Headey D, Hoddinott J, Park S. Drivers of nutritional change in four south Asian countries: a dynamic observational analysis. Maternal \& Child Nutrition. 2016;12:210-8

66. Martorell $\mathrm{R}$, Zongrone A. Intergenerational influences on child growth and undernutrition. Paediatr Perinat Epidemiol. 2012;26(Suppl 1):302-14.

67. Kramer MS. The epidemiology of adverse pregnancy outcomes: an overview. J Nutr. 2003;133:1592s-6s.

68. Maternal anthropometry and pregnancy outcomes. A WHO Collaborative Study. Bull World Health Organ. 1995;73 Suppl:1-98.

69. Acharya S, Sharma S, Dulal B, Aryal K. Quality of Care and Client Satisfaction with Maternal Health Services in Nepal: Further Analysis of the 2015 Nepal Health Facility Survey. DHS Further Analysis Reports No. 112. Rockville, Maryland, USA: ICF; 2018.

70. Kruk ME, Gage AD, Arsenault C, Jordan K, Leslie HH, Roder-DeWan S, Adeyl O, Barker P, Daelmans B, Doubova SV, et al. High-quality health systems in the sustainable development goals era: time for a revolution. Lancet Glob Health.

71. Royston P, Altman DG, Sauerbrei W. Dichotomizing continuous predictors in multiple regression: a bad idea. Stat Med. 2006:25:127-41.

72. Howe LD, Hargreaves JR, Huttly SR. Issues in the construction of wealth indices for the measurement of socio-economic position in low-income countries. Emerg Themes Epidemiol. 2008;5:3.
73. Asian Development Bank: Country Poverty Analysis Nepal Manila, Philippines Asian Development Bank; 2013.

74. National Planning Commission [Government of Nepal]. Nepal's Multidimensional Poverty Index: Analysis Towards Action. Kathmandu: National Planning Commission; 2018.

75. Bhutta ZA, Bang A, Afsana K, Gyawali B, Mirzazada S, Jayatissa R. Rethinking community based strategies to tackle health inequities in South Asia. Bmj. 2018;363:k4884
Ready to submit your research? Choose BMC and benefit from:

- fast, convenient online submission

- thorough peer review by experienced researchers in your field

- rapid publication on acceptance

- support for research data, including large and complex data types

- gold Open Access which fosters wider collaboration and increased citations

- maximum visibility for your research: over $100 \mathrm{M}$ website views per year

At BMC, research is always in progress.

Learn more biomedcentral.com/submissions 